\title{
Alcohol Consumption and Binge Drinking Among Young Adults Aged 20-30 Years in Lisbon, Portugal
}

Moutinho, Lídia Susana Mendes; de Oliveira Cruz Mendes, Aida Maria; Lopes, Manuel

Journal of Addictions Nursing: October/December 2018 - Volume 29 - Issue 4 - p E9-E15

doi: 10.1097/JAN.0o0oooooooooo255

Original Articles

\section{Abstract Author Informationuthors Article Metrißsetrics}

Background: Over the past decade, the changes to the pattern of alcohol consumption in Portugal, in particular among young people with heavy episodic drinking (binge drinking), are well documented. However, there are limited studies in individuals aged between 20 and 30 years, which is an important period of transition into adulthood where binge drinking can negatively influence the resolution of developmental tasks. Therefore, this study aims at analyzing the pattern of alcohol consumption and binge drinking among young adults aged between 20 and 30 years living in the municipality of Lisbon.

Methodology: This is a quantitative, descriptive correlational study using a convenience sample composed of 259 individuals. We used the Alcohol Use Disorders Identification Test for data collection.

Results: Among the sampled subjects, 19.3\% of them reported being nondrinkers. Among the alcohol-drinking subjects $(N=209), 61.3 \%$ reported binge drinking behaviors. We found a higher percentage of binge drinkers among vocational training students than among university students, as well as a relatively higher percentage of women. In both cases, we found no statistically significant differences. Within the total sample, $10.8 \%$ reported hazardous or harmful consumption, with men showing greater hazardous consumption.

Conclusions: Although approximately one fifth of the sampled subjects reported being nondrinkers, the percentage of binge drinkers in this study was significantly higher than that reported in other studies. We also found that binge drinking is more common among vocational training students, although this difference was not statistically significant. Further studies are needed on this age group and in nonacademic settings.

Lídia Susana Mendes Moutinho, Centro Hospitalar Psiquiátrico de Lisboa, Unidade de Tratamento e Reabilitação Alcoólica, Portugal

Aida Maria de Oliveira Cruz Mendes, Escola Superior de Enfermagem de Coimbra, Unidade de Investigação em Ciências da Saúde: Enfermagem, Portugal.

Manuel Lopes, Escola Superior de Enfermagem de S. João de Deus, Universidade de Évora, Portugal.

The authors report no conflicts of interest. The authors alone are responsible for the content and writing of the article.

Correspondence related to content to: Lídia Susana Mendes Moutinho, Centro Hospitalar Psiquiátrico de Lisboa, Unidade de Tratamento e Reabilitação Alcoólica, Rua Martin Luther King 12, 10 A, 1750-053 Lisboa, Portugal. Email: lidiamoutinho@live.com.pt

(C) 2018International Nurses Society on Addictions

$\triangle$ You currently do not have access to this article

To access this article: 
- Register an account

- Log in to LWW if you are a registered subscriber

- Subscribe to this Journal, or

- Purchase access to this article if you are not a subscriber

- View this article in Ovid if your institution subscribes to this journal.

Note: If your society membership provides full-access, you may need to login on your society website 